Review

\title{
Serine and one-carbon metabolisms bring new therapeutic venues in prostate cancer
}

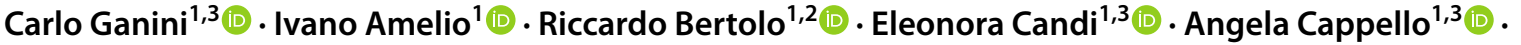

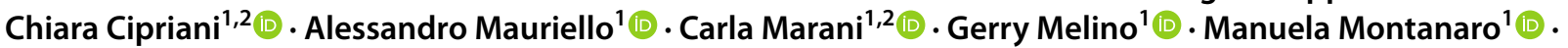 \\ Maria Emanuela Natale ${ }^{1,2} \cdot$ Giuseppe Tisone $^{1}(\mathbb{D}) \cdot$ Yufang Shi $^{1,4,5} \cdot$ Ying Wang $^{4}$ (D) Pierluigi Bove $^{1,2}$ (i)
}

Received: 27 July 2021 / Accepted: 14 October 2021

Published online: 27 October 2021

(c) The Author(s) $2021 \quad$ OPEN

\begin{abstract}
Serine and one-carbon unit metabolisms are essential biochemical pathways implicated in fundamental cellular functions such as proliferation, biosynthesis of important anabolic precursors and in general for the availability of methyl groups. These two distinct but interacting pathways are now becoming crucial in cancer, the de novo cytosolic serine pathway and the mitochondrial one-carbon metabolism. Apart from their role in physiological conditions, such as epithelial proliferation, the serine metabolism alterations are associated to several highly neoplastic proliferative pathologies. Accordingly, prostate cancer shows a deep rearrangement of its metabolism, driven by the dependency from the androgenic stimulus. Several new experimental evidence describes the role of a few of the enzymes involved in the serine metabolism in prostate cancer pathogenesis. The aim of this study is to analyze gene and protein expression data publicly available from large cancer specimens dataset, in order to further dissect the potential role of the abovementioned metabolism in the complex reshaping of the anabolic environment in this kind of neoplasm. The data suggest a potential role as biomarkers as well as in cancer therapy for the genes (and enzymes) belonging to the one-carbon metabolism in the context of prostatic cancer.
\end{abstract}

Keywords Serine $\cdot$ One-carbon metabolism · Prostate cancer metabolism

Carlo Ganini, carlo.ganini@students.uniroma2.eu; $₫$ Pierluigi Bove, pierluigi.bove@uniroma2.it; Ivano Amelio, ivano.amelio@uniroma2.it; Riccardo Bertolo, riccardobertolo@hotmail.it; Eleonora Candi, candi@uniroma2.it; Angela Cappello, angela.cappello1993@gmail.com; Chiara Cipriani, chiaracipriani88@gmail.com; Alessandro Mauriello, alessandro.mauriello@uniroma2.it; Carla Marani, karlamarani@yahoo.it; Gerry Melino, melino@uniroma2.it; Manuela Montanaro, manuelamontanaro1991@gmail.com; Maria Emanuela Natale, m.emanuelanatale@gmail.com; Giuseppe Tisone, tisone@med.uniroma2.it; Yufang Shi, yufangshi@sibs.ac.cn; Ying Wang, yingwang@sibs.ac.cn | ${ }^{1}$ Department of Experimental Medicine, Torvergata Oncoscience Research Centre of Excellence, TOR, University of Rome Tor Vergata, a Montpellier 1, 00133 Rome, Italy. ${ }^{2}$ San Carlo di Nancy Hospital, Rome, Italy. IDI-IRCCS, Rome, Italy. ${ }^{4}$ CAS Key Laboratory of Tissue Microenvironment and Tumor, Shanghai Institute of Nutrition and Health, Shanghai Institutes for Biological Sciences, University of Chinese Academy of Sciences, Chinese Academy of Sciences, 320 Yueyang Road, Shanghai 200031, China. ${ }^{5}$ The First Affiliated Hospital of Soochow University and State Key Laboratory of Radiation Medicine and Protection, Institutes for Translational Medicine, Soochow University, 199 Renai Road, Suzhou 215123, Jiangsu, China. 


\section{One-carbon metabolism in cancer}

Cancer cells can adapt their metabolism to achieve proliferation and survival benefits. The initial evidence for this observation can be attributed to Otto Warburg who demonstrated that cancer cells compared to normal cells increase aerobic glycolysis (Warburg effect) [1, 2]. In general, metabolic changes have been thoroughly studied and incorporated in the cancer hallmarks [3-5].

The involvement of one-carbon (1C) metabolism in cancer transformation has been just recently discovered getting intense interest in the last decades. The term "one-carbon metabolism" refers to a complex network of metabolic reactions, closely related and fundamental for cell energy production. The fulcrum is represented by folate metabolism [6]. 1C metabolism is essential to form, activate and transfer one-carbon units for different biosynthetic processes such us purine and thymidine synthesis and homocysteine remethylation [7].

The term folate indicates a series of molecules that share a common biochemical structure with three chemical moieties: a pteridine ring that can be reduced or oxidized, a para-aminobenzoic acid (PABA) linker that, together with the pteridine ring, binds $1 \mathrm{C}$ units and a variable chain length polyglutamate tail, that localizes the molecule within the cell. The biologically active form of folate is the reduced form tetrahydrofolate (THF); in humans, almost all natural folate species either taken from the diet or present in the body are in their reduced form of 5-methyl-THF [8].

1C metabolism can also been considered as an interlinked network of biosynthetic pathways, including serine metabolism, that allows the conversion of serine and tetrahydrofolate to glycine and $5^{\prime}-10^{\prime}$ methylenetetrahydrofolate (5'-10' meTHF), the glycine cleavage system (GCS) and the metabolism of choline and methionine (Fig. 1).

In general, this metabolic network allows cells to generate one-carbon units (methyl groups) and to utilize them for the biosynthesis of important anabolic precursors and for methylation reactions [9-11].

Several studies have highlighted an increased activation of two pathways that are involved in $1 \mathrm{C}$ metabolism in cancer: the de novo serine pathway and the mitochondrial 1C pathway $[12,13]$.

Consistent DNA synthesis is a fundamental request for cancer cells to sustain their proliferative capacity; therefore, multiple $1 \mathrm{C}$ metabolic enzymes are upregulated in cancer [14].

The importance of one-carbon metabolism in cancer was initially recognized in 1948, when Sydney Farber observed that dietary folate deficiency in children with acute leukemia reduced their leukemic cell number. Using the folic acid antagonist aminopterin in these patients it was possible to produce a temporary regression of the disease. These discoveries led to the development of the class of drugs known as antifolates [15].

One-carbon units are necessary for the biosynthesis of both purine and pyrimidine nucleotides, essential for DNA and RNA synthesis. Purine nucleotides are synthetized from ribose-5-phosphate, generated by the pentose phosphate pathway. Inosine monophosphate (IMP), the precursor to all purine nucleotides, is produced through a series of reaction, which require the incorporation of two one-carbon units and one molecule of glycine [16].

Depletion of serine, which is a substrate for glycine production, inhibits proliferation and reduces the level of purine nucleotides in cancer cells [17].

One-carbon units are also utilized to produce pyrimidine nucleotides and thymidylate. The thymidylate synthase (TYMS) enzyme can form dTMP from dUMP using methylene-THF as the methyl donor. Folate deficiency and methotrexate treatment can inhibit dTMP synthesis to such a degree that uracil is incorporated into DNA in its place [18, 19].

Cancer cells often show alterations in the patterns of DNA methylation and one-carbon metabolism represents the major source of methyl-group (one carbon units) utilized for DNA modification. DNA methylation regulates gene expression and hyper-methylation of promoters of tumor suppressor genes leads to a reduction in their expression. RNA is also subjected to methylation that can regulate translation. In addition, proteins can be post-translationally modified by methylation, which can alter their function or protein-protein interactions [20, 21].

$S$-Adenosylmethionine (SAM) is a universal methyl donor. Upon the transfer of its methyl group to an acceptor such as DNA, SAM becomes S-adenosylhomocysteine, which is converted to homocysteine. Homocysteine can be recycled back to methionine by the contribution of a methyl group from methyl-THF. Therefore, the primary role of serine is to support the methionine cycle to provide one-carbon units for methionine recycling through the reduction of THF to maintain the $S$-adenosylmethionine pool $[1,22,23]$.

In addition, one-carbon metabolism plays a role in the production of NADH and NADPH, important cofactors that provide electrons for redox reactions. Enzymes that resynthesize THF can use NADH and NADPH as cofactors. As an example, during anabolism, the enzyme methylenetetrahydrofolate dehydrogenase (MTHFD) catalyzes the conversion of methylene-THF to formyl-THF for purine biosynthesis and NAD $(P)+$ is used as a cofactor and reduced 


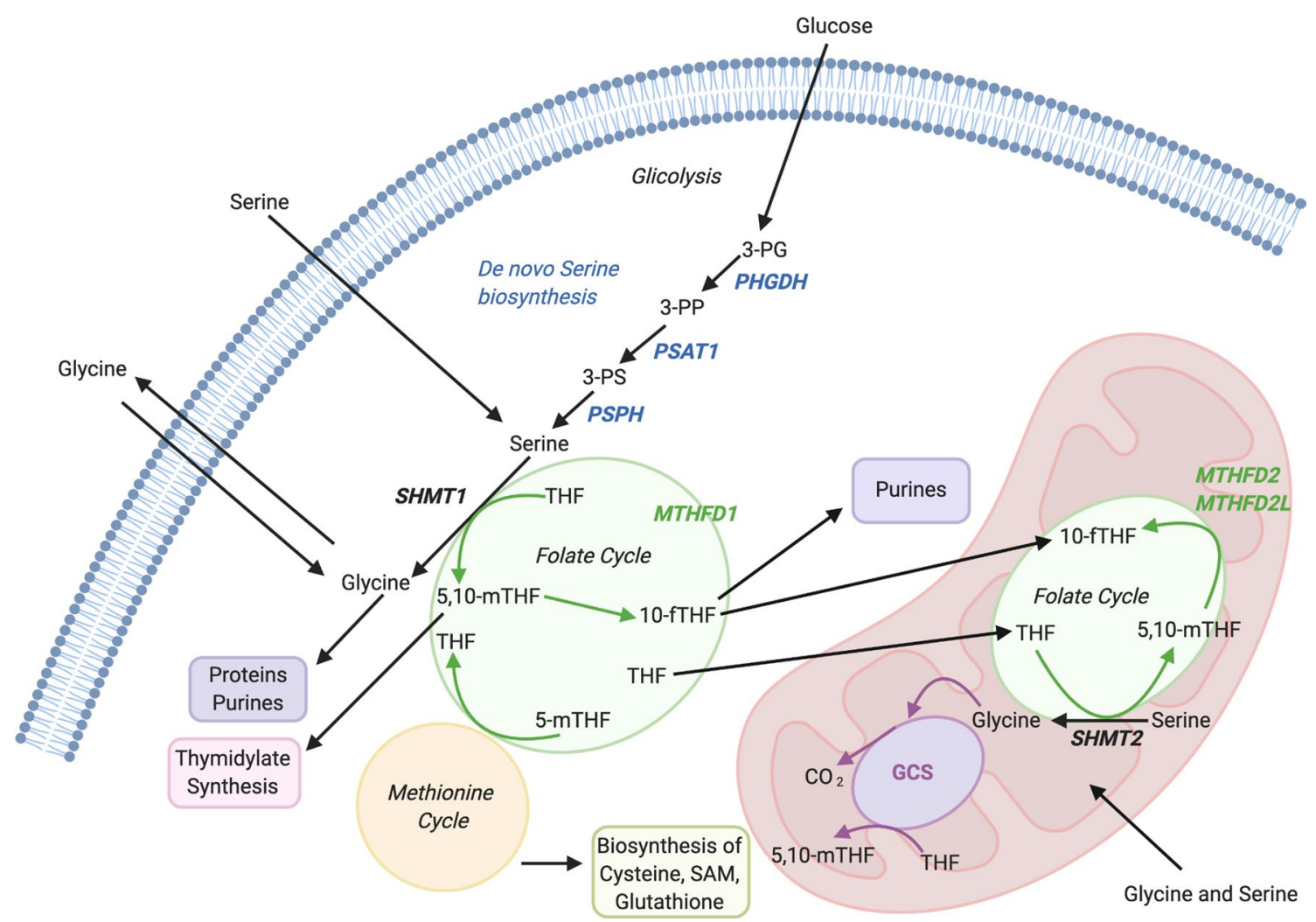

Fig. 1 Schematic representation of the one-carbon metabolism. The schematic image describes biochemical pathway involved in serine and glycine biosynthesis and in one carbon metabolism, a group of reactions necessary to production of proteins, purines, thymidylate, methionine, cysteine, S-adenosyl-methionine (SAM) and glutathione. Regarding one-carbon units, the current image shows a strong metabolic connection between cytoplasmatic, and mitochondrial enzymes involved in THF production, serine de novo biosynthesis and serine and glycine catabolism. Cytoplasmatic enzymes: $P H G D H$ phosphoglycerate dehydrogenase, PSAT1 phosphoserine aminotransferase 1, PSPH phosphoserine phosphatase, SHMT1 serine hydroxymethyltransferase 1; mitochondrial enzymes: SHMT2 serine hydroxymethyltransferase 2, MTHFD1 methylenetetrahydrofolate dehydrogenase1, MTHFD2 methylenetetrahydrofolate dehydrogenase2, MTHFD2L methylenetetrahydrofolate dehydrogenase NADP+ dependent 2 like, GCS glycine cleavage system. Biochemical compounds: 3-PG 3-phospoglycerate, 3-PP 3-phosphopyruvate, 3-PS 3-phosposerine, THF tetrahydrofolate, 5,10-me-THF 5,10-methylenetetrahydrofolate, 5-me-THF 5-methylenetetrahydrofolate, 10-f-THF 10-formate-tetrahydrofolate

to NAD(P)H in this reaction. The mitochondrial forms of this enzyme, MTHFD2 and MTHFD2L, can use either NAD+ or NADP+ as a cofactor, whereas the cytosolic form, MTHFD1, specifically uses NAD+ [24, 25].

Moreover, the $1 \mathrm{C}$ metabolism is also involved in the oxidative status homeostasis of the cell, since it is associated to the replenishments of glutathione through the pairing of the folate cycle and the methionine cycle [26-28] and in the immune/inflammatory response, so crucial during cancer progression [29-32]. This might also be ideal in the context of therapeutic intervention on the oxidative status of cancers in which the $1 \mathrm{C}$ metabolism is altered [33-35].

Serine and glycine are two fundamental amino acids that provide the precursors for the synthesis of proteins, nucleic acids, and lipids. Serine and glycine contribute to cellular metabolism by providing one-carbon units which refuels onecarbon metabolism in the cell [36-38].

This happens thanks to the presence of enzymes which can convert serine in glycine with one-carbon units formation; then glycine is further metabolized [37-39].

In eukaryotic cells, there are two different biosynthetic pathways producing serine: the de novo serine pathway and the serine recycling pathway, which is mediated by the Serine hydroxy-methyltransferases enzymes (SHMTs) and the folate cycle $[40,41]$.

Serine hydroxymethyl transferases are pyridoxal 5'-phosphate-(PLP) dependent enzyme that catalyze the reversible transfer of $\beta$ carbon from L-serine to tetrahydrofolate (THF), with the sequent generation of glycine and 5,10-methyleneTHF. This reaction represents the primary source of the one-carbon units required for the synthesis of thymidylate, purines, and methionine. Moreover, SHMTs in vitro are also able to catalyze THF-independent transamination, racemization, decarboxylation, condensation, and retroaldol cleavage reactions [42]. 
In some lung, ovarian and breast cancers SHMT1 acts as an oncoprotein, promoting tumor progression. The role of SHMT1 in hepatocellular carcinomas is still unclear, although some recent studies revealed a significantly decreased expression of SHMT1. This reduction is possibly correlated to adverse clinical features and poor prognosis of these cancer patients.

In several types of cancer an accentuated deregulation of SHMT2 is observed and is often associated with tumor progression. For example, in vitro studies of hepatocellular carcinoma cells show that inhibition of SHMT2 significantly decreases tumor progression while its overexpression is insufficient to induce tumor transformation, thus suggesting that SHMT2 is involved in tumorigenesis but it is not able to start malignant transformation alone. Anyhow, both the enzymes are somehow de-regulated by many modalities in the context of cancer [43-45].

\section{Serine metabolism in prostate cancer}

In the pathogenesis of prostate cancer, the initial pathogenetic event might be considered the dependency from the androgen stimulation [46-50], but many more molecular alterations have been found associated to its progression [51-55] as well as to the development of specific clinical features of the disease such as bone metastasis [56] or studied as potential therapeutic targets [57]. The microbiome has also been shown to impact on the pathogenesis of this kind of cancer [58-62], also due to development of algorithms allowing to interpret its role in the context of a disease [63-67]. Anyhow, specific attention is focused on epigenetic remodeling.

DNA methylation has been associated to prostate cancer pathogenesis under different aspects such as in response to radiotherapy [68] or in the tracking of circulating tumor DNA [69] where androgen receptor sequences are hypomethylated in the blood stream and correlate with a poorer prognosis, suggesting also a possible role in liquid biopsies [70-75] and the overcome of the classical histology based biopsies $[76,77]$. The methylation of the DNA strongly depends on the availability of methyl groups, by the activity of the enzymes involved in the $1 \mathrm{C}$ unit metabolism. An alteration of this metabolic pathway has therefore been explored, beneath partially, in the context of prostatic cancer.

The enzymes involved in the one-carbon metabolism have been evaluated in a prostate cancer population through genomic sequencing defining at least two methionine synthase gene (MTR) polymorphisms ( $r s 2837281 \mathrm{~T}>\mathrm{G}$ and rs $1131450 \mathrm{G}>\mathrm{A}$ ) associated to a poorer prognosis in the Han Chinese population [78]. Moreover, folate depletion has been shown to induce transcriptional reprogramming and to reshape DNA damage response and the DNA methylation pattern in a human xenograft model of prostate cancer following androgen withdrawal [79-82].

Anyhow, the one-carbon metabolism has also been implied in the pathogenesis of the highly resistant to treatment neuroendocrine histotype of prostatic cancer (NEPC) [83-86] since the de-regulation of protein kinase $C$ (characteristic in NEPC) upregulates serine biosynthesis and SAM intracellular levels which allow the epigenetic reshaping of this peculiar type of cancer [87-89].

Prostate cancer has also been shown to depend on the activity of the methyladenosine phosphorylase enzyme (MTAP), the rate-limiting enzyme of the methionine cycle, which is used by prostatic cells to overcome the loss of carbon units in the secretion of polyamines. The dual inhibition on polyamines secretion and of MTAP has proved to induce apoptosis in ex-vivo explants [90].

Finally, the central component of the mitochondrial one-carbon metabolism MTHFD2 is upregulated in prostate cancer from at least two transcription factors ATF4 and c-Myc, which have already been implicated in this disease and its silencing inhibits prostate cancer cells growth as well as prostatosphere formation [91, 92].

Consistently with this preliminary evidence of an alteration of some of the one-carbon metabolism component in prostate cancer at different stages of the disease, we performed a bioinformatic analysis on publicly available gene expression and clinical data from the TCGA (Firehose Legacy) [93-95], comprehensive of 499 samples of prostate cancer specimens. The database has been explored using the cBioportal online platform $[96,97]$ and the GEPIA web server [98].

\section{Alterations of one-carbon and serine metabolism in a cohort of prostatic cancer patients from TCGA}

The analysis of the expression of genes involved in serine and glycine metabolism has been evaluated (Fig. 2A). Phosphoserine phosphatase (PSPH), whose role in lung cancer has already been explored [99], shows a relatively high percentage of alteration in the prostate cancer cohort, up to $11 \%$ of the specimens, mostly due to gene overexpression 
A

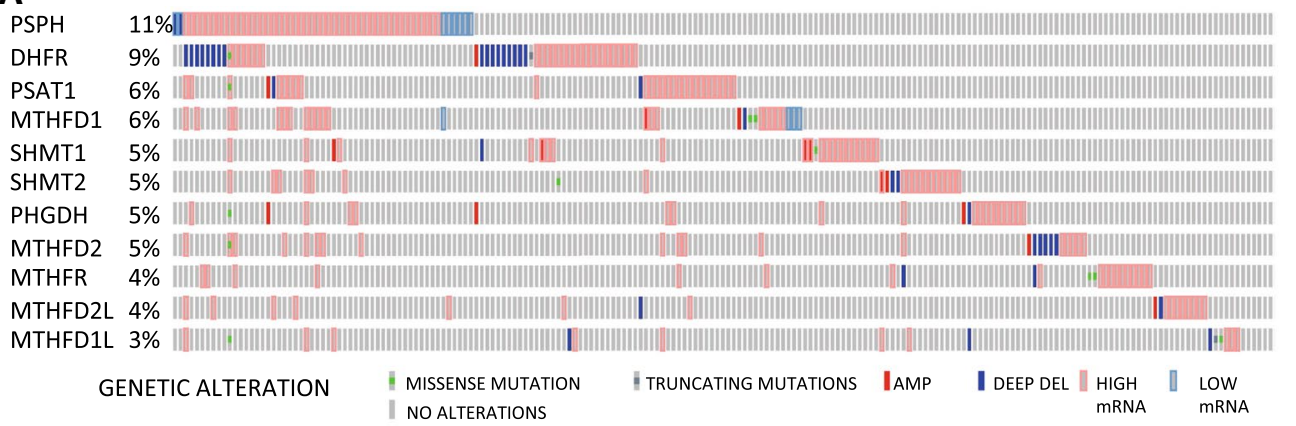

B

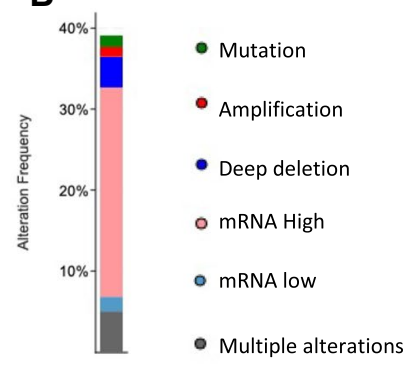

C

\begin{tabular}{|c|c|c|c|c|c|c|c|c|}
\hline GENE A & GENE B & A Not B & B Not A & Both & Log2 Odds Ratio & $p$-Value & $q$-Value & Tendency \\
\hline MTHFR & MTHFD2 & 11 & 12 & 6 & $>3$ & $<0.001$ & 0.003 & Co-occurrence \\
\hline PSPH & MTHFD1 & 29 & 9 & 8 & $>3$ & $<0.001$ & 0.003 & Co-occurrence \\
\hline PSPH & DHFR & 26 & 22 & 11 & 2.464 & $<0.001$ & 0.003 & Co-occurrence \\
\hline PSAT1 & MTHFD2L & 16 & 7 & 5 & $>3$ & $<0.001$ & 0.004 & Co-occurrence \\
\hline PSAT1 & MTHFD1 & 16 & 12 & 5 & $>3$ & 0.002 & 0.021 & Co-occurrence \\
\hline
\end{tabular}

D

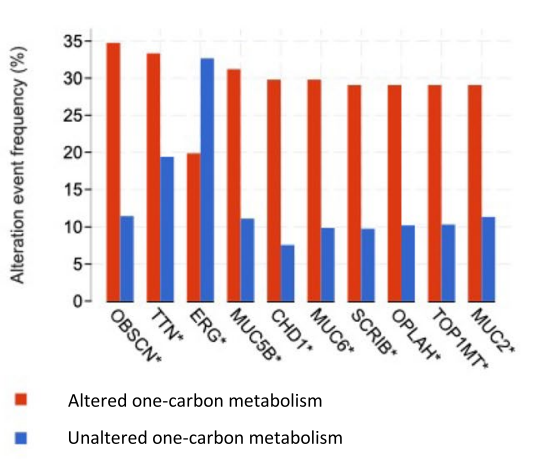

E

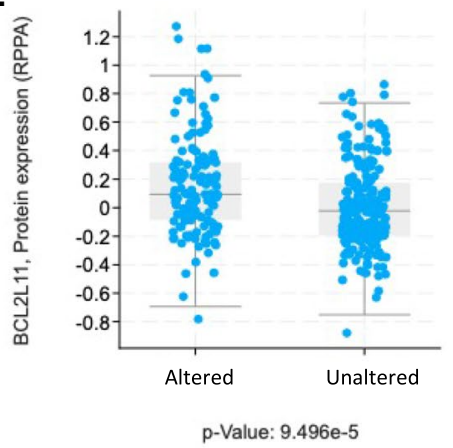

q-Value: 0.0191

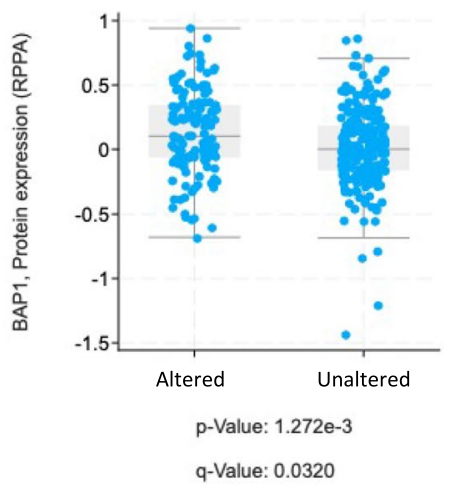

Fig. 2 One-carbon metabolism enzymes in prostate cancer overview. A OncoPrint profiling of genetic or expression alteration in genes involved in the one-carbon metabolism in a cohort of 498 patients from TCGA (AMP, amplification, DEL, deletion); B cumulative alteration frequency of the one-carbon enzymes analysed; $\mathbf{C}$ co-occurrence analysis of the alterations of transcription the one-carbon enzymes genes, p-values are derived from one-sided Fisher Exact Test, q-values are derived from Benjamini-Hochberg FDR correction procedure; D genomic alteration frequency of known prostate cancer driver genes in one-carbon metabolism genes altered group vs control; E log2 scale protein expression of BCL2L11 and BAP1 in one-carbon metabolism genes altered group vs control, p-values are calculated from Student's T-test, q-values are calculated from Benjamini-Hochberg procedure

(except for a few cases in which the gene is deleted). Dehydrofolate reductase (DHFR) [100] is the second most altered gene in the $9 \%$ of all cases. Differently form PSPH the DHFR gene does not have a clear pattern of alteration, showing gene overexpression in almost half of the cases in which the alteration is present, followed by downregulation. SHMT1 and SHMT2 $[25,101,102]$ enzymes show altered expression in $5 \%$ of the cases, comparably to the other genes which are essentially involved in the folate cycle. From this analysis it is evident that in prostate cancer samples in which there is an alteration in one of the genes related to the one-carbon metabolism, it is quite probable that other genes from the pathway are altered so that it is unlikely that a single gene is the only one whose expression is perturbed. This might suggest that the reshape of the serine metabolism in prostate cancer is a pervasive metabolic event that is in place to adapt the transformed cell to gain selective advantage.

As a matter of fact, all together these genes are altered in nearly $40 \%$ of cancer specimens and most of the alterations of the genes involved in serine and glycine metabolism are due to increased expression of the relative mRNA rather that due to mutation. This evidence might still suggest that the serine and glycine metabolism is more an adaptive event, rather than a driver genetic aberration of the cancer itself (Fig. 2B). 
As shown on Fig. 2A, there is a tendency to find more than one gene from the one-carbon metabolism altered in a single prostate cancer. This evidence can be further dissected showing that many genes have a statistically significative co-occurrence trend: methylene-tetrahydro-folate reductase MTHFR) is altered in samples in which also the MTHFD2 gene is altered $(p<0.001, q=0.003)$, while PSPH overexpression is associated to MTHFD1 and DHFR $(p<0.001, q=0.003$ for both), which is also the case for PSAT1 and MTHFD2L ( $p<0.001, q=0.003)$, or with MTHFD1 ( $<<0.001, q=0.004)$ (Fig. 2C).

Consistently with the role played by the one-carbon metabolism in providing carbon units which are partially used to synthesize $S$-adenosyl-methionine, and its effect on the epigenetic remodeling of the chromatin, it is quite interesting to observe that in the serine metabolism altered group of patients (comprising all the patients showing one alteration in at least one of the genes shown in Fig. $1 \mathrm{~A}$ ) there is a relatively higher alteration (considering any kind of event, form mRNA over- or down-expression, to mutations, etc.) in many genes which are considered cancer drivers in prostate cancer, such as obscurin (OBSCN) [37], titin (TTN) [103], the ETS transcription factor (ERG) [104] and many mucins (MUC5B, MUC6, MUC2) $[105,106]$ (Fig. 2D). Alteration of the serine metabolism might therefore show promising therapeutic approaches if its role in epigenetic remodeling of prostate cancer is confirmed.

Serine metabolism reshaping in prostate cancer might also plays a rather pervasive rearrangement of cellular metabolism and expression profile and might be associated to changes of the expression of many more genes which have been clearly associated to tumor genesis and progression such as the apoptotic protein BCL2L11 [107-111] (more expressed in the group of patients harboring a perturbation of the serine metabolism, $p<0.001$ and $q<0.001$ ) and well as the chromatin remodeler BAP1 [112] (less expressed in the altered groups, $p<0.001 \mathrm{q}=0.003$ ) (Fig. 2E).

\section{Mutational status and copy number alterations of one-carbon metabolism enzymes in prostate cancer patients}

As said initially, genes in the serine metabolism are rarely mutated in prostate cancer. The most reported mutations are for the PSPH gene, with a mutation in its HAD domain, in DHFR, in PSAT1 and in the FTHFS domain of the MTHFD1 gene (Fig. 3A).

Since the genes involved in the serine metabolism are mostly subject to expression alteration, an analysis on the putative copy-number alteration form GISTIC shows a relatively increasing cumulative alteration in cancer specimens with higher Gleason scores (>7), except for Gleason 10 cases which are just less abundant among all the cases and show quite a substantial number of samples harboring copy-number modifications (Fig. 3B).

Some of the genes involved in the serine metabolism are differentially expressed between prostate cancer tissue and the surrounding normal prostate epithelium as in the case of PSAT1, overexpressed in the tumor $(p<0.005)$ (Fig. 4A). PSAT1 expression also shows a strong direct positive correlation with the expression of MTHFD2 gene with Spearman coefficient $=0.48(p<0.001)$ and Pearson coefficient $=0.54(p<0.001)$ (Fig. 4B).

\section{One-carbon and serine metabolism impact on prostate cancer progression}

The progression of prostate cancer involves several molecular mechanisms, underlying a complex regulation of autophagy [113-117], micro-RNA [118-122], p53 [123-126], Bcl-2 [127, 128] family and interleukins [31, 32, 129, 130] able to also impinge on the above-mentioned metabolisms.

Therefore, the analysis followed considering correlation to clinical data, the analysis of the disease-free survival (DFS) of patients stratified according to the expression levels of some of the key genes involved in the serine metabolisms fails in showing statistically significant differences among the groups for PSAT1 (Fig. 4C) as well for SHMT1, SHMT2 and MTHFD1L where, anyhow, high expression shows a tendency to a worse disease course with higher number of progressions (Figs. 4D-F). Anyhow, grouping all the possible alterations in the genes involved in the serine metabolism stratifying patients between the altered and the unaltered group, there is a strong difference in terms of progression free survival with a better prognosis for the unaltered group $(p<0.001)$ (Fig. $4 G)$, this might be regarded as the development of a potential prediction algorithm as already done in many other clinical contexts [131-134].

Apart from a possible role of the enzymes involved in the 1C metabolism as potential biomarker of progression in prostate cancer (specifically as a molecular signature) this metabolism might also represent a therapeutic option to be explored in this clinical context. The overall management of this cancer depends on a combined approach relying on surgery, radiotherapy, hormonal therapy or chemotherapy, depending on the status of the disease [135]. When 
A

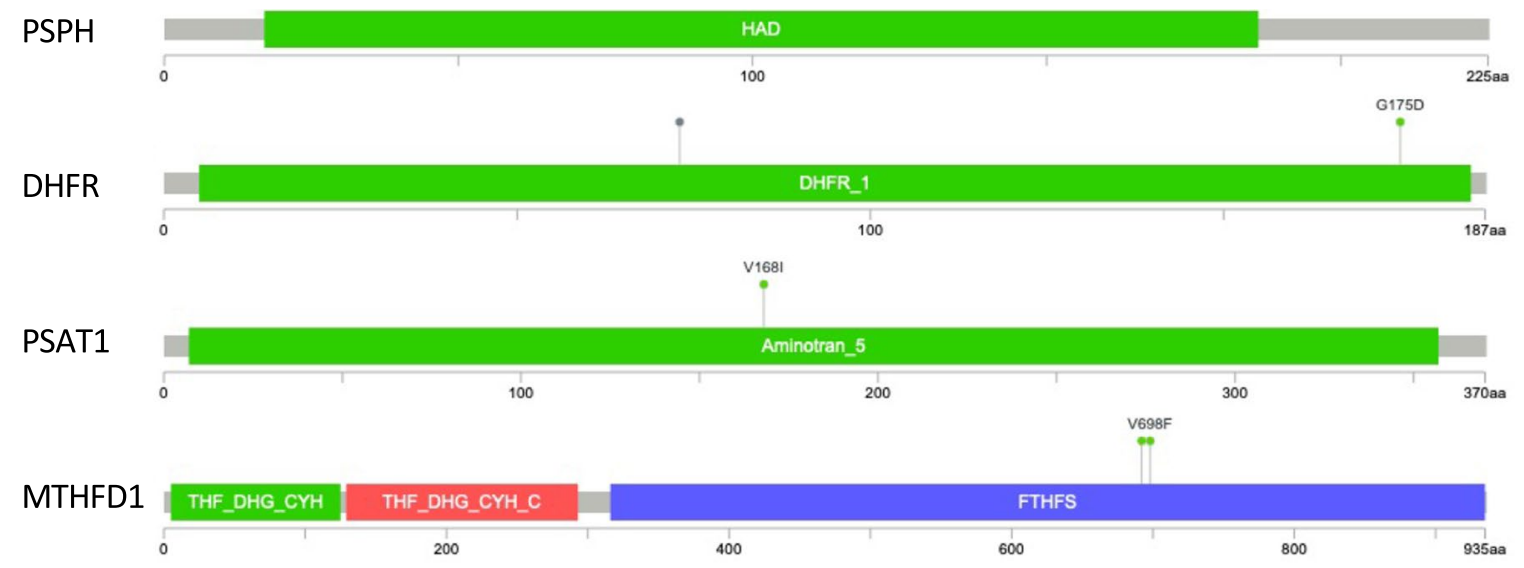

B

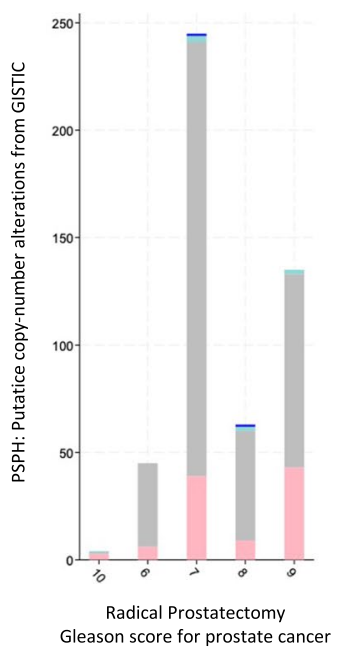

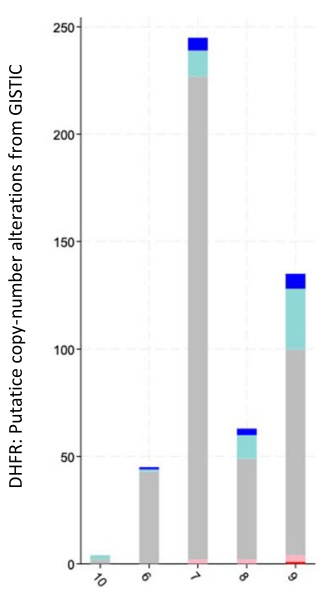

Radical Prostatectomy Gleason score for prostate cancer

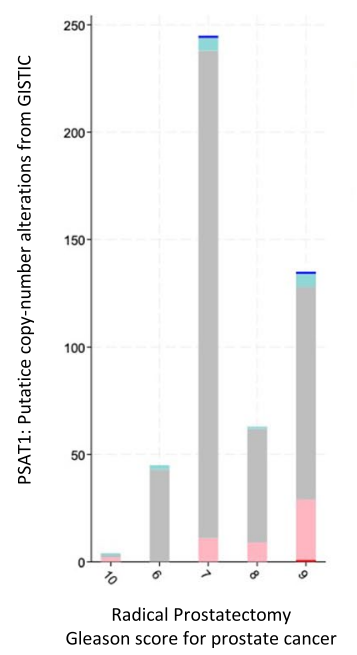

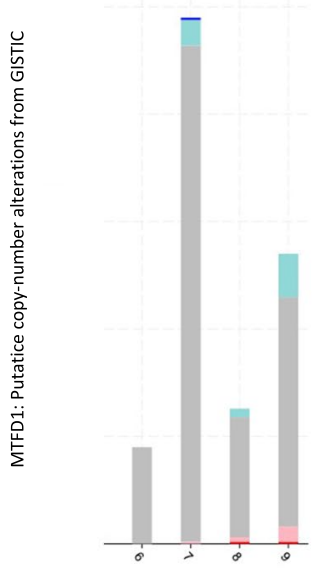

Radical Prostatectomy Gleason score for prostate cancer

Fig. 3 One-carbon metabolism enzymes mutations and correlation with Gleason score. A Schematic representation of the top four altered one-carbon metabolism genes and mutations in the TCGA analysed cohort; B putative copy-number alterations number of samples over the total 499 samples analysed in the TCGA Firehose Legacy cohort, of the top four altered one-carbon metabolism genes in groups of prostate cancer patients stratified according to Gleason score after radical prostatectomy

chemotherapy is necessary, often in the case of tumors which show resistance to androgen deprivation therapy or inhibition of androgen synthesis, the use of microtubules synthesis inhibitors is the standard of care with drugs such as docetaxel or cabazitaxel [136]. Anyhow, resistance to these treatments, as well as resistance to targeted therapies (PARP inhibitors) can occur and potential alternative strategies are required. The inhibition of one-carbon metabolism, with an anti-folate therapy, might represent a significative option to be explored in a clinical context, and some data on the use of methotrexate, a known anti-folate drug, show efficacy in reducing prostate cancer progression in combination with luteinizing hormone releasing hormone, in cell lines end mouse xenograft models $[137,138]$. The effect of the inhibition of the one carbon metabolism, should anyway be regarded with caution, since its impact on the immune system, inducing immunosuppression, might play a contradictory result promoting cancer progression [139].

\section{Conclusion}

Despite being and extremely preliminary evaluation of the possible role of serine and one-carbon metabolism in prostate cancer, the present review shows that a pervasive alteration of these biochemical pathways is abundantly evoked during prostatic cancer pathogenesis and evolution. Anyhow, the analysis is quite partial due to the heterogeneity of the cohort of patients and the evaluation of the expression of genes at an RNA level rather than at a protein level. To address this specific issue, a multi-omics approach [140] might be beneficial for the dissection of complex metabolic scenarios like 
A
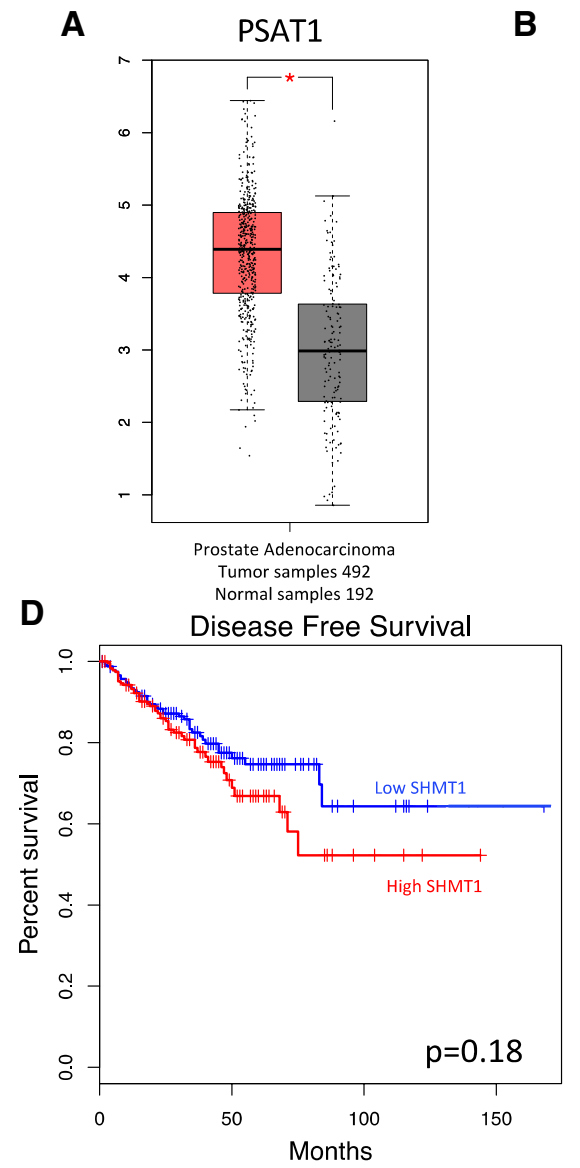

B
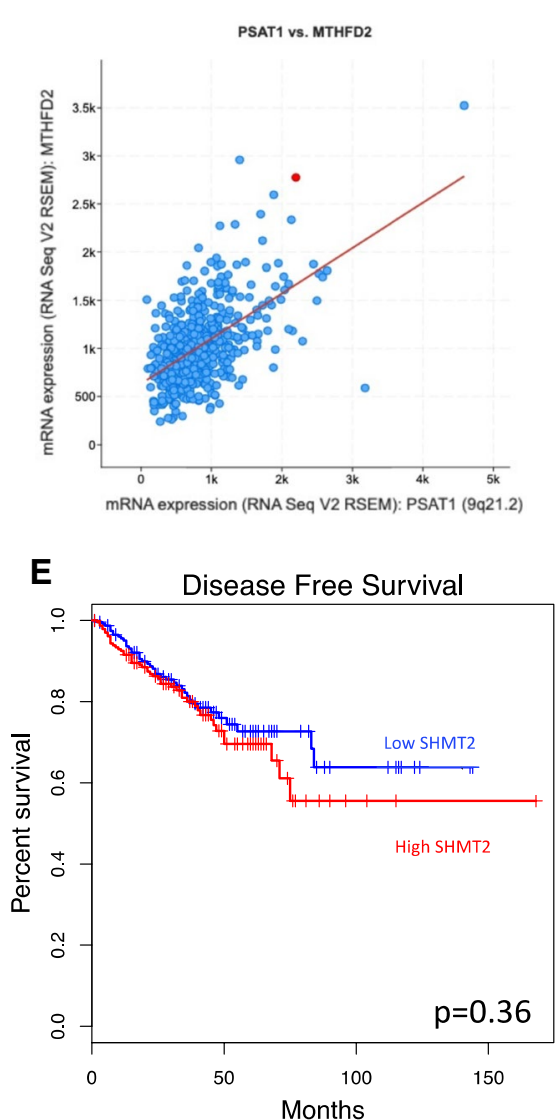

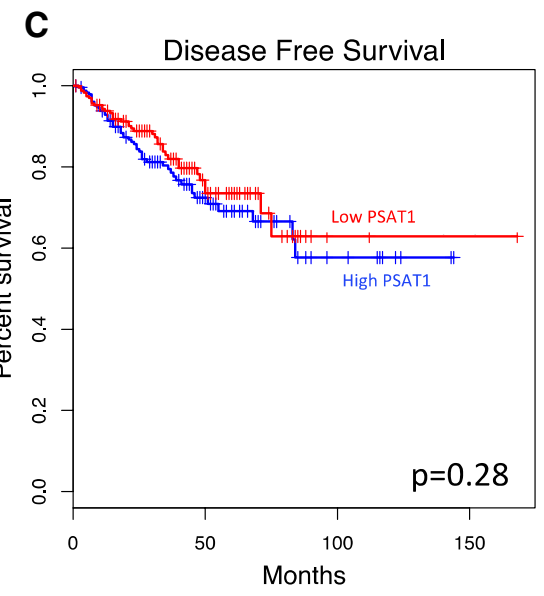

$\mathbf{F}$

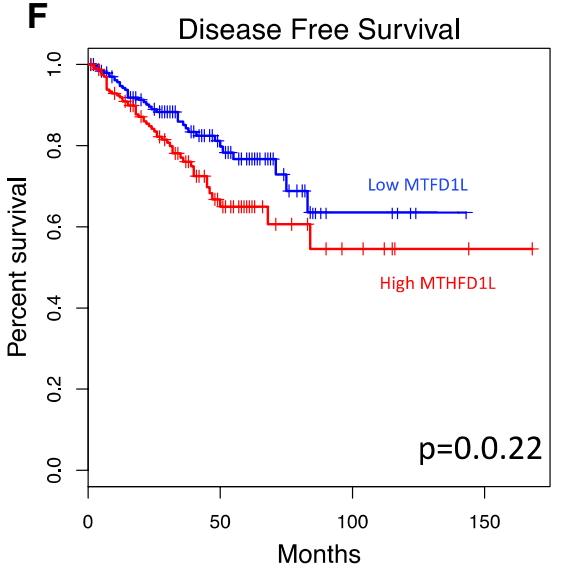

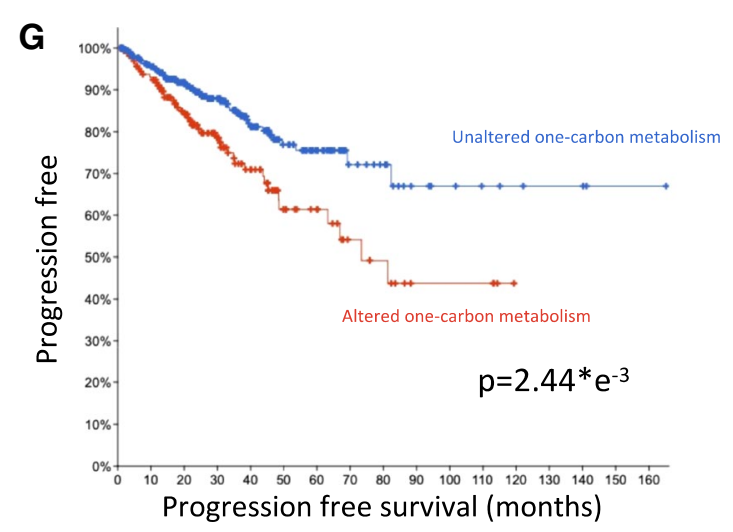

Fig. 4 One-carbon metabolism enzymes clinical correlations. A PSAT1 log scale differential gene expression between prostate cancer tissues compared to normal matching controls (GEPIA), p-value is calculated applying the one-way ANOVA statistical method; B mRNA expression correlation of PSAT1 and MTHFD2 enzymes in prostate cancer tissues, Spearman coefficient 0.48 ( $p<0.001$, two-sided T-test) Pearson coefficient 0.54 ( $p<0.001$, two-sided T-test); $\mathbf{C}-\mathbf{F}$ disease-free survival Kaplan-Meier plots stratifying patients according to expression levels of PSAT1 (C), SHMT1 (D), SHMT2 (E) and MTHFD1 (F) (GEPIA), p-values are calculated applying the log-rank test; $\mathbf{G}$ cumulative one-carbon metabolism alterations and progression-free survival of prostate cancer patients from TCGA (cBioportal), $p$-values calculated using the Logrank test

the one described. Of course, the generation of omics data and further analysis should rely on the developing machine learning algorithms [141, 142], allowing to detect molecular signatures among cancer specimens through the analysis of big data repositories.

Moreover, alteration at the levels of such a complex metabolism might also be exploited in order to develop biomarker for prediction or monitoring of the progression of the disease [77, 143, 144], as it is happening in the context of other types of cancer $[145,146]$. 
Acknowledgements We apologize for those whose contributions could not be cited due to space constraints. Figure parts, as well as whole figures, have been generated using Biorender.com.

Authors' contributions CG, AC and PB wrote the manuscript. CG and AC prepared the figures. All the other indicated authors (IA, RB, EC, CC, $\mathrm{AM}, \mathrm{CM}, \mathrm{GM}, \mathrm{MM}, \mathrm{EMN}, \mathrm{GT}, \mathrm{YS}, \mathrm{YW}$ ) made substantial contribution to the conception of the manuscript and critically revised it. All authors read and approved the final manuscript.

Funding This work has been supported by the Associazione Italiana per la Ricerca contro il Cancro (AIRC) to GM (IG\#20473; 2018-2022), to IA (AIRC Start-Up ID 23219; 2020-2024), to EC (IG\#22206; 2019-2023), Ministry of Health \& MAECI Italy-China Science and Technology Cooperation (\#PGR00961) to EC, GM and YW, Ministry of Health and IDI-IRCCS (RF2019.12368888) to EC.

\section{Declarations}

Competing interests The authors declare no conflict of interest.

Open Access This article is licensed under a Creative Commons Attribution 4.0 International License, which permits use, sharing, adaptation, distribution and reproduction in any medium or format, as long as you give appropriate credit to the original author(s) and the source, provide a link to the Creative Commons licence, and indicate if changes were made. The images or other third party material in this article are included in the article's Creative Commons licence, unless indicated otherwise in a credit line to the material. If material is not included in the article's Creative Commons licence and your intended use is not permitted by statutory regulation or exceeds the permitted use, you will need to obtain permission directly from the copyright holder. To view a copy of this licence, visit http://creativecommons.org/licenses/by/4.0/.

\section{References}

1. Newman AC, Maddocks ODK. One-carbon metabolism in cancer. Br J Cancer. 2017;116(12):1499-504.

2. Lonetto G, Koifman G, Silberman A, Attery A, Solomon H, Levin-Zaidman S, et al. Mutant p53-dependent mitochondrial metabolic alterations in a mesenchymal stem cell-based model of progressive malignancy. Cell Death Differ. 2019;26(9):1566-81.

3. Liu H, He Z, Germic N, Ademi H, Frangez Z, Felser A, et al. ATG12 deficiency leads to tumor cell oncosis owing to diminished mitochondrial biogenesis and reduced cellular bioenergetics. Cell Death Differ. 2020;27(6):1965-80.

4. Hanahan D, Weinberg RA. Hallmarks of cancer: the next generation. Cell. 2011;144(5):646-74.

5. Dobon B, Montanucci L, Pereto J, Bertranpetit J, Laayouni H. Gene connectivity and enzyme evolution in the human metabolic network. Biol Direct. 2019;14(1):17.

6. Locasale JW. Serine, glycine and one-carbon units: cancer metabolism in full circle. Nat Rev Cancer. 2013;13(8):572-83.

7. Ducker GS, Rabinowitz JD. One-carbon metabolism in health and disease. Cell Metab. 2017;25(1):27-42.

8. Wright AJ, Dainty JR, Finglas PM. Folic acid metabolism in human subjects revisited: potential implications for proposed mandatory folic acid fortification in the UK. Br J Nutr. 2007;98(4):667-75.

9. Mattaini KR, Sullivan MR, Vander Heiden MG. The importance of serine metabolism in cancer. J Cell Biol. 2016;214(3):249-57.

10. Parker SJ, Metallo CM. Chasing one-carbon units to understand the role of serine in epigenetics. Mol Cell. 2016;61(2):185-6.

11. Jing YY, Cai FF, Zhang L, Han J, Yang L, Tang F, et al. Epigenetic regulation of the Warburg effect by H2B monoubiquitination. Cell Death Differ. 2020;27(5):1660-76.

12. Pike ST, Rajendra R, Artzt K, Appling DR. Mitochondrial C1-tetrahydrofolate synthase (MTHFD1L) supports the flow of mitochondrial one-carbon units into the methyl cycle in embryos. J Biol Chem. 2010;285(7):4612-20.

13. Zheng Y, Lin TY, Lee G, Paddock MN, Momb J, Cheng Z, et al. Mitochondrial one-carbon pathway supports cytosolic folate integrity in cancer cells. Cell. 2018;175(6):1546-1560.e17.

14. Mehrmohamadi M, Liu X, Shestov AA, Locasale JW. Characterization of the usage of the serine metabolic network in human cancer. Cell Rep. 2014;9(4):1507-19.

15. Farber S, Diamond LK. Temporary remissions in acute leukemia in children produced by folic acid antagonist, 4-aminopteroyl-glutamic acid. N Engl J Med. 1948;238(23):787-93.

16. Zhu D, Zhao Z, Cui G, Chang S, Hu L, See YX, et al. Single-cell transcriptome analysis reveals estrogen signaling coordinately augments one-carbon, polyamine, and purine synthesis in breast cancer. Cell Rep. 2019;27(9):2798.

17. Maddocks OD, Berkers CR, Mason SM, Zheng L, Blyth K, Gottlieb E, et al. Serine starvation induces stress and p53-dependent metabolic remodelling in cancer cells. Nature. 2013;493(7433):542-6.

18. Goulian M, Bleile B, Tseng BY. The effect of methotrexate on levels of dUTP in animal cells. J Biol Chem. 1980;255(22):10630-7.

19. Goulian M, Bleile B, Tseng BY. Methotrexate-induced misincorporation of uracil into DNA. Proc Natl Acad Sci USA. 1980;77(4):1956-60.

20. Fu Y, Dominissini D, Rechavi G, He C. Gene expression regulation mediated through reversible m(6)A RNA methylation. Nat Rev Genet. 2014; 15(5):293-306.

21. Perna S, Pinoli P, Ceri S, Wong L. NAUTICA: classifying transcription factor interactions by positional and protein-protein interaction information. Biol Direct. 2020;15(1):13.

22. Guo T, Gong C, Wu P, Battaglia-Hsu SF, Feng J, Liu P, et al. LINC00662 promotes hepatocellular carcinoma progression via altering genomic methylation profiles. Cell Death Differ. 2020;27(7):2191-205.

23. Chu YD, Lai HY, Pai LM, Huang YH, Lin YH, Liang KH, et al. The methionine salvage pathway-involving ADI1 inhibits hepatoma growth by epigenetically altering genes expression via elevating S-adenosylmethionine. Cell Death Dis. 2019;10(3):240. 
24. Meiser J, Vazquez A. Give it or take it: the flux of one-carbon in cancer cells. FEBS J. 2016;283(20):3695-704.

25. Meiser J, Tumanov S, Maddocks O, Labuschagne CF, Athineos D, Van Den Broek N, et al. Serine one-carbon catabolism with formate overflow. Sci Adv. 2016;2(10):e1601273.

26. Vitali A, Botta B, Delle Monache G, Zappitelli S, Ricciardi P, Melino S, et al. Purification and partial characterization of a peroxidase from plant cell cultures of Cassia didymobotrya and biotransformation studies. Biochem J. 1998;331(Pt 2):513-9.

27. Zhou X, He L, Wu C, Zhang Y, Wu X, Yin Y. Serine alleviates oxidative stress via supporting glutathione synthesis and methionine cycle in mice. Mol Nutr Food Res. 2017;61(11):1700262.

28. Angelucci S, Sacchetta P, Moio P, Melino S, Petruzzelli R, Gervasi P, et al. Purification and characterization of glutathione transferases from the sea bass (Dicentrarchus labrax) liver. Arch Biochem Biophys. 2000;373(2):435-41.

29. Newman AC, Falcone M, Huerta Uribe A, Zhang T, Athineos D, Pietzke M, et al. Immune-regulated IDO1-dependent tryptophan metabolism is source of one-carbon units for pancreatic cancer and stellate cells. Mol Cell. 2021;81(11):2290-2302.e7.

30. Kurniawan H, Kobayashi T, Brenner D. The emerging role of one-carbon metabolism in T cells. Curr Opin Biotechnol. $2021 ; 68: 193-201$.

31. Franzè E, Dinallo V, Rizzo A, Di Giovangiulio M, Bevivino G, Stolfi C, et al. Interleukin-34 sustains pro-tumorigenic signals in colon cancer tissue. Oncotarget. 2018;9(3):3432-45.

32. Franze E, Marafini I, De Simone V, Monteleone I, Caprioli F, Colantoni A, et al. Interleukin-34 induces Cc-chemokine ligand 20 in gut epithelial cells. J Crohns Colitis. 2016;10(1):87-94.

33. Sabelli R, lorio E, De Martino A, Podo F, Ricci A, Viticchie G, et al. Rhodanese-thioredoxin system and allyl sulfur compounds. FEBS J. 2008;275(15):3884-99.

34. Cabras T, Patamia M, Melino S, Inzitari R, Messana I, Castagnola M, et al. Pro-oxidant activity of histatin 5 related Cu(II)-model peptide probed by mass spectrometry. Biochem Biophys Res Commun. 2007;358(1):277-84.

35. Nepravishta R, Sabelli R, lorio E, Micheli L, Paci M, Melino S. Oxidative species and S-glutathionyl conjugates in the apoptosis induction by allyl thiosulfate. FEBS J. 2012;279(1):154-67.

36. Amelio I, Cutruzzola F, Antonov A, Agostini M, Melino G. Serine and glycine metabolism in cancer. Trends Biochem Sci. 2014;39(4):191-8.

37. Tajan M, Hennequart M, Cheung EC, Zani F, Hock AK, Legrave N, et al. Serine synthesis pathway inhibition cooperates with dietary serine and glycine limitation for cancer therapy. Nat Commun. 2021;12(1):366.

38. Zhuang H, Wu F, Wei W, Dang Y, Yang B, Ma X, et al. Glycine decarboxylase induces autophagy and is downregulated by miRNA-30d-5p in hepatocellular carcinoma. Cell Death Dis. 2019;10(3):192.

39. Fan TWM, Bruntz RC, Yang Y, Song H, Chernyavskaya Y, Deng P, et al. De novo synthesis of serine and glycine fuels purine nucleotide biosynthesis in human lung cancer tissues. J Biol Chem. 2019;294(36):13464-77.

40. Lee D, Wong CC. The folate cycle is a new metabolic weakness of cancer. Mol Cell Oncol. 2017;4(6):e1327004.

41. Li T, Weng J, Zhang Y, Liang K, Fu G, Li Y, et al. mTOR direct crosstalk with STAT5 promotes de novo lipid synthesis and induces hepatocellular carcinoma. Cell Death Dis. 2019;10(8):619.

42. Angelaccio S. Extremophilic SHMTs: from structure to biotechnology. Biomed Res Int. 2013;2013:851428.

43. Lin C, Zhang Y, Chen Y, Bai Y, Zhang Y. Long noncoding RNA LINC01234 promotes serine hydroxymethyltransferase 2 expression and proliferation by competitively binding miR-642a-5p in colon cancer. Cell Death Dis. 2019;10(2):137.

44. Bouzidi A, Magnifico MC, Paiardini A, Macone A, Boumis G, Giardina G, et al. Cytosolic serine hydroxymethyltransferase controls lung adenocarcinoma cells migratory ability by modulating AMP kinase activity. Cell Death Dis. 2020;11(11):1012.

45. Woo CC, Chen WC, Teo XQ, Radda GK, Lee PT. Downregulating serine hydroxymethyltransferase 2 (SHMT2) suppresses tumorigenesis in human hepatocellular carcinoma. Oncotarget. 2016;7(33):53005-17.

46. Deng G, Wang R, Sun Y, Huang CP, Yeh S, You B, et al. Targeting androgen receptor (AR) with antiandrogen enzalutamide increases prostate cancer cell invasion yet decreases bladder cancer cell invasion via differentially altering the AR/circRNA-ARC1/miR-125b-2-3p or miR-4736/PPARgamma/MMP-9 signals. Cell Death Differ. 2021;28(7):2145-59.

47. Guo F, Zhang C, Wang F, Zhang W, Shi X, Zhu Y, et al. Deubiquitinating enzyme USP33 restrains docetaxel-induced apoptosis via stabilising the phosphatase DUSP1 in prostate cancer. Cell Death Differ. 2020;27(6):1938-51.

48. Chou FJ, Lin C, Tian H, Lin W, You B, Lu J, et al. Preclinical studies using cisplatin/carboplatin to restore the enzalutamide sensitivity via degrading the androgen receptor splicing variant 7 (ARv7) to further suppress enzalutamide resistant prostate cancer. Cell Death Dis. 2020;11(11):942.

49. Gasca J, Flores ML, Jimenez-Guerrero R, Saez ME, Barragan I, Ruiz-Borrego M, et al. EDIL3 promotes epithelial-mesenchymal transition and paclitaxel resistance through its interaction with integrin alphaVbeta3 in cancer cells. Cell Death Discov. 2020;6:86.

50. Gupta S, Pungsrinont T, Zenata O, Neubert L, Vrzal R, Baniahmad A. Interleukin-23 represses the level of cell senescence induced by the androgen receptor antagonists enzalutamide and darolutamide in castration-resistant prostate cancer cells. Horm Cancer. 2020;11(3-4):182-90.

51. Ju LG, Zhu Y, Long QY, Li XJ, Lin X, Tang SB, et al. SPOP suppresses prostate cancer through regulation of CYCLIN E1 stability. Cell Death Differ. 2019;26(6):1156-68.

52. He Z, Shen F, Qi P, Zhai Z, Wang Z. miR-541-3p enhances the radiosensitivity of prostate cancer cells by inhibiting HSP27 expression and downregulating beta-catenin. Cell Death Discov. 2021;7(1):18.

53. Chowdhury S, Beitel LK, Lumbroso R, Purisima EO, Paliouras M, Trifiro M. A targeted bivalent androgen receptor binding compound for prostate cancer therapy. Horm Cancer. 2019;10(1):24-35.

54. Neuzillet Y, Raynaud JP, Dreyfus JF, Radulescu C, Rouanne M, Schneider M, et al. Aggressiveness of localized prostate cancer: the key value of testosterone deficiency evaluated by both total and bioavailable testosterone: AndroCan study results. Horm Cancer. 2019;10(1):36-44.

55. Sileri P, Sica G, Gentileschi P, Venza M, Manzelli A, Palmieri G, et al. Ischemic preconditioning protects intestine from prolonged ischemia. Transplant Proc. 2004;36(2):283-5.

56. Velletri T, Huang Y, Wang Y, Li Q, Hu M, Xie N, et al. Loss of $\mathrm{p} 53$ in mesenchymal stem cells promotes alteration of bone remodeling through negative regulation of osteoprotegerin. Cell Death Differ. 2021;28(1):156-69.

57. Soll M, Chen QC, Zhitomirsky B, Lim PP, Termini J, Gray HB, et al. Protein-coated corrole nanoparticles for the treatment of prostate cancer cells. Cell Death Discov. 2020;6:67. 
58. Javier-DesLoges J, McKay RR, Swafford AD, Sepich-Poore GD, Knight R, Parsons JK. The microbiome and prostate cancer. Prostate Cancer Prostatic Dis. 2021. https://doi.org/10.1038/s41391-021-00413-5.

59. Alanee S, El-Zawahry A, Dynda D, McVary K, Karr M, Braundmeier-Fleming A. Prospective examination of the changes in the urinary microbiome induced by transrectal biopsy of the prostate using 16S rRNA gene analysis. Prostate Cancer Prostatic Dis. 2019;22(3):446-52.

60. Banerjee S, Alwine JC, Wei Z, Tian T, Shih N, Sperling C, et al. Microbiome signatures in prostate cancer. Carcinogenesis. 2019;40(6):749-64.

61. Chen JC, Tyler AD. Systematic evaluation of supervised machine learning for sample origin prediction using metagenomic sequencing data. Biol Direct. 2020;15(1):29.

62. Huang L, Xu C, Yang W, Yu R. A machine learning framework to determine geolocations from metagenomic profiling. Biol Direct. 2020;15(1):27.

63. Harris ZN, Dhungel E, Mosior M, Ahn TH. Massive metagenomic data analysis using abundance-based machine learning. Biol Direct. 2019;14(1):12.

64. Ryan FJ. Application of machine learning techniques for creating urban microbial fingerprints. Biol Direct. 2019;14(1):13.

65. Kawulok J, Kawulok M, Deorowicz S. Environmental metagenome classification for constructing a microbiome fingerprint. Biol Direct. 2019;14(1):20.

66. Bellomaria A, Barbato G, Melino G, Paci M, Melino S. Recognition of p63 by the E3 ligase ITCH: effect of an ectodermal dysplasia mutant. Cell Cycle. 2010;9(18):3730-9.

67. Bellomaria A, Barbato G, Melino G, Paci M, Melino S. Recognition mechanism of p63 by the E3 ligase Itch: novel strategy in the study and inhibition of this interaction. Cell Cycle. 2012;11(19):3638-48.

68. Sutton LP, Jeffreys SA, Phillips JL, Taberlay PC, Holloway AF, Ambrose M, et al. DNA methylation changes following DNA damage in prostate cancer cells. Epigenetics. 2019;14(10):989-1002.

69. Wu A, Cremaschi P, Wetterskog D, Conteduca V, Franceschini GM, Kleftogiannis D, et al. Genome-wide plasma DNA methylation features of metastatic prostate cancer. J Clin Invest. 2020;130(4):1991-2000.

70. Bakavicius A, Daniunaite K, Zukauskaite K, Barisiene M, Jarmalaite S, Jankevicius F. Urinary DNA methylation biomarkers for prediction of prostate cancer upgrading and upstaging. Clin Epigenet. 2019;11(1):115.

71. Zhao F, Vesprini D, Liu RSC, Olkhov-Mitsel E, Klotz LH, Loblaw A, et al. Combining urinary DNA methylation and cell-free microRNA biomarkers for improved monitoring of prostate cancer patients on active surveillance. Urol Oncol. 2019;37(5):297.e9-297.e17.

72. Amelio I, Bertolo R, Bove P, Candi E, Chiocchi M, Cipriani C, et al. Cancer predictive studies. Biol Direct. 2020;15(1):18.

73. Signore M, Alfonsi R, Federici G, Nanni S, Addario A, Bertuccini L, et al. Diagnostic and prognostic potential of the proteomic profiling of serum-derived extracellular vesicles in prostate cancer. Cell Death Dis. 2021;12(7):636.

74. Amelio I, Bertolo R, Bove P, Buonomo OC, Candi E, Chiocchi M, et al. Liquid biopsies and cancer omics. Cell Death Discov. $2020 ; 6(1): 131$.

75. Vanden Berghe T, Hoste E. Paving the way for precision medicine v2.0 in intensive care by profiling necroinflammation in biofluids. Cell Death Differ. 2019;26(1):83-98.

76. Rossi P, Sileri P, Gentileschi P, Sica GS, Forlini A, Stolfi VM, et al. Percutaneous liver biopsy using an ultrasound-guided subcostal route. Dig Dis Sci. 2001;46(1):128-32.

77. Biancone L, Onali S, Calabrese E, Petruzziello C, Zorzi F, Condino G, et al. Non-invasive techniques for assessing postoperative recurrence in Crohn's disease. Dig Liver Dis. 2008;40(Suppl 2):S265-70.

78. Qu YY, Zhou SX, Zhang X, Zhao R, Gu CY, Chang K, et al. Functional variants of the 5-methyltetrahydrofolate-homocysteine methyltransferase gene significantly increase susceptibility to prostate cancer: results from an ethnic Han Chinese population. Sci Rep. 2016;6:36264.

79. Affronti HC, Long MD, Rosario SR, Gillard BM, Karasik E, Boerlin CS, et al. Dietary folate levels alter the kinetics and molecular mechanism of prostate cancer recurrence in the CWR22 model. Oncotarget. 2017;8(61):103758-74.

80. Vanzo R, Bartkova J, Merchut-Maya JM, Hall A, Bouchal J, Dyrskjot L, et al. Autophagy role(s) in response to oncogenes and DNA replication stress. Cell Death Differ. 2020;27(3):1134-53.

81. Gallo M, Paludi D, Cicero DO, Chiovitti K, Millo E, Salis A, et al. Identification of a conserved N-capping box important for the structural autonomy of the prion alpha 3-helix: the disease associated D202N mutation destabilizes the helical conformation. Int J Immunopathol Pharmacol. 2005;18(1):95-112.

82. Melino S, Nepravishta R, Bellomaria A, Di Marco S, Paci M. Nucleic acid binding of the RTN1-C C-terminal region: toward the functional role of a reticulon protein. Biochemistry. 2009;48(2):242-53.

83. Long Z, Deng L, Li C, He Q, He Y, Hu X, et al. Loss of EHF facilitates the development of treatment-induced neuroendocrine prostate cancer. Cell Death Dis. 2021;12(1):46.

84. Shan J, Al-Muftah MA, Al-Kowari MK, Abuaqel SWJ, Al-Rumaihi K, Al-Bozom I, et al. Targeting Wnt/EZH2/microRNA-708 signaling pathway inhibits neuroendocrine differentiation in prostate cancer. Cell Death Discov. 2019;5:139.

85. Pinto MP, Munoz Medel M, Carrillo D, Retamal IN, Bravo ML, Valenzuela Y, et al. Chilean registry for neuroendocrine tumors: a Latin American perspective. Horm Cancer. 2019;10(1):3-10.

86. Herrera-Martinez AD, Feelders RA, de Herder WW, Castano JP, Galvez Moreno MA, Dogan F, et al. Effects of ketoconazole on ACTHproducing and non-ACTH-producing neuroendocrine tumor cells. Horm Cancer. 2019;10(2-3):107-19.

87. Reina-Campos M, Linares JF, Duran A, Cordes T, L'Hermitte A, Badur MG, et al. Increased serine and one-carbon pathway metabolism by PKClambda/iota deficiency promotes neuroendocrine prostate cancer. Cancer Cell. 2019;35(3):385-400.e9.

88. Gao X, Locasale JW, Reid MA. Serine and methionine metabolism: vulnerabilities in lethal prostate cancer. Cancer Cell. 2019;35(3):339-41.

89. Aqeilan RI. Engineering organoids: a promising platform to understand biology and treat diseases. Cell Death Differ. 2021;28(1):1-4.

90. Affronti HC, Rowsam AM, Pellerite AJ, Rosario SR, Long MD, Jacobi JJ, et al. Pharmacological polyamine catabolism upregulation with methionine salvage pathway inhibition as an effective prostate cancer therapy. Nat Commun. 2020;11(1):52.

91. Pallmann N, Deng K, Livgard M, Tesikova M, Jin Y, Frengen NS, et al. Stress mediated reprogramming of prostate cancer one-carbon cycle drives disease progression. Cancer Res. 2021;81(15):4066-78.

92. Cheung CHY, Hsu CL, Tsuei CY, Kuo TT, Huang CT, Hsu WM, et al. Combinatorial targeting of MTHFD2 and PAICS in purine synthesis as a novel therapeutic strategy. Cell Death Dis. 2019;10(11):786. 
93. Larmuseau M, Verbeke LPC, Marchal K. Associating expression and genomic data using co-occurrence measures. Biol Direct. $2019 ; 14(1): 10$.

94. Pallucca R, Visconti S, Camoni L, Cesareni G, Melino S, Panni S, et al. Specificity of epsilon and non-epsilon isoforms of arabidopsis 14-3-3 proteins towards the H+-ATPase and other targets. PLoS ONE. 2014;9(6):e90764.

95. Aceto A, Dragani B, Melino S, Allocati N, Masulli M, Di Ilio C, et al. Identification of an N-capping box that affects the alpha 6-helix propensity in glutathione S-transferase superfamily proteins: a role for an invariant aspartic residue. Biochem J. 1997;322(Pt 1):229-34.

96. Gao J, Aksoy BA, Dogrusoz U, Dresdner G, Gross B, Sumer SO, et al. Integrative analysis of complex cancer genomics and clinical profiles using the cBioPortal. Sci Signal. 2013;6(269):pl1.

97. Cerami E, Gao J, Dogrusoz U, Gross BE, Sumer SO, Aksoy BA, et al. The cBio cancer genomics portal: an open platform for exploring multidimensional cancer genomics data. Cancer Discov. 2012;2(5):401-4.

98. Tang Z, Li C, Kang B, Gao G, Li C, Zhang Z. GEPIA: a web server for cancer and normal gene expression profiling and interactive analyses. Nucleic Acids Res. 2017;45(W1):W98-102.

99. Liao L, Ge M, Zhan Q, Huang R, Ji X, Liang X, et al. PSPH mediates the metastasis and proliferation of non-small cell lung cancer through MAPK signaling pathways. Int J Biol Sci. 2019;15(1):183-94.

100. Zawiah M, Yousef AM, Kadi T, Yousef M, Majdalawi K, Al-Yacoub S, et al. Early disease relapse in a patient with colorectal cancer who harbors genetic variants of DPYD, TYMS, MTHFR and DHFR after treatment with 5-fluorouracil-based chemotherapy. Drug Metab Pers Ther. 2018;33(4):201-5.

101. Paone A, Marani M, Fiascarelli A, Rinaldo S, Giardina G, Contestabile R, et al. SHMT1 knockdown induces apoptosis in lung cancer cells by causing uracil misincorporation. Cell Death Dis. 2014;5:e1525.

102. Scaletti E, Jemth AS, Helleday T, Stenmark P. Structural basis of inhibition of the human serine hydroxymethyltransferase SHMT2 by antifolate drugs. FEBS Lett. 2019;593(14):1863-73.

103. Zhu Y, Yang Z, Luo XH, Xu P. Long noncoding RNA TTN-AS1 promotes the proliferation and migration of prostate cancer by inhibiting miR-1271 level. Eur Rev Med Pharmacol Sci. 2021;25(3):1165.

104. Nicholas TR, Strittmatter BG, Hollenhorst PC. Oncogenic ETS factors in prostate cancer. Adv Exp Med Biol. 2019;1210:409-36.

105. Andren O, Fall K, Andersson SO, Rubin MA, Bismar TA, Karlsson M, et al. MUC-1 gene is associated with prostate cancer death: a 20-year follow-up of a population-based study in Sweden. Br J Cancer. 2007;97(6):730-4.

106. Slovin SF, Ragupathi G, Fernandez C, Jefferson MP, Diani M, Wilton AS, et al. A bivalent conjugate vaccine in the treatment of biochemically relapsed prostate cancer: a study of glycosylated MUC-2-KLH and Globo H-KLH conjugate vaccines given with the new semi-synthetic saponin immunological adjuvant GPI-0100 OR QS-21. Vaccine. 2005;23(24):3114-22.

107. Singh PK, Roukounakis A, Weber A, Das KK, Sohm B, Villunger A, et al. Dynein light chain binding determines complex formation and posttranslational stability of the Bcl-2 family members Bmf and Bim. Cell Death Differ. 2020;27(2):434-50.

108. Lucantoni F, Salvucci M, Dussmann H, Lindner AU, Lambrechts D, Prehn JHM. BCL(X)L and BCL2 increase the metabolic fitness of breast cancer cells: a single-cell imaging study. Cell Death Differ. 2021;28(5):1512-31.

109. Schulman JJ, Szczesniak LM, Bunker EN, Nelson HA, Roe MW, Wagner LE 2nd, et al. Bok regulates mitochondrial fusion and morphology. Cell Death Differ. 2019;26(12):2682-94.

110. Yang Y, Chen D, Liu H, Yang K. Increased expression of IncRNA CASC9 promotes tumor progression by suppressing autophagy-mediated cell apoptosis via the AKT/mTOR pathway in oral squamous cell carcinoma. Cell Death Dis. 2019;10(2):41.

111. Greaves G, Milani M, Butterworth M, Carter RJ, Byrne DP, Eyers PA, et al. BH3-only proteins are dispensable for apoptosis induced by pharmacological inhibition of both MCL-1 and BCL-XL. Cell Death Differ. 2019;26(6):1037-47.

112. Masclef L, Ahmed O, Estavoyer B, Larrivee B, Labrecque N, Nijnik A, et al. Roles and mechanisms of BAP1 deubiquitinase in tumor suppression. Cell Death Differ. 2021;28(2):606-25.

113. He C, Fu Y, Chen Y, Li X. Long non-coding RNA SNHG8 promotes autophagy as a ceRNA to upregulate ATG7 by sponging microRNA-588 in colorectal cancer. Oncol Lett. 2021;22(2):577.

114. Zhou LY, Zhai M, Huang Y, Xu S, An T, Wang YH, et al. The circular RNA ACR attenuates myocardial ischemia/reperfusion injury by suppressing autophagy via modulation of the Pink1/ FAM65B pathway. Cell Death Differ. 2019;26(7):1299-315.

115. Yang Y, Klionsky DJ. Autophagy and disease: unanswered questions. Cell Death Differ. 2020;27(3):858-71.

116. Fan Y, Hou T, Gao Y, Dan W, Liu T, Liu B, et al. Acetylation-dependent regulation of TPD52 isoform 1 modulates chaperone-mediated autophagy in prostate cancer. Autophagy. 2021. https://doi.org/10.1080/15548627.2021.1917130.

117. Mulcahy Levy JM, Thorburn A. Autophagy in cancer: moving from understanding mechanism to improving therapy responses in patients. Cell Death Differ. 2020;27(3):843-57.

118. Doldi V, El Bezawy R, Zaffaroni N. MicroRNAs as epigenetic determinants of treatment response and potential therapeutic targets in prostate cancer. Cancers. 2021;13(10):2380.

119. Wang X, Yang JY, Cai J, Zhang DJ, Zhao L, Luo LH, et al. MiR-543/Numb promotes proliferation, metastasis, and stem-like cell traits of prostate cancer cells. Am J Transl Res. 2021;13(2):617-31.

120. Barlak N, Capik O, Kilic A, Sanli F, Aytatli A, Yazici A, et al. MicroRNA-145 transcriptionally regulates Semaphorin 3A expression in prostate cancer cells. Cell Biol Int. 2021;45(5):1082-90.

121. Chen Y, Yang F, Fang E, Xiao W, Mei H, Li H, et al. Circular RNA circAGO2 drives cancer progression through facilitating HuR-repressed functions of AGO2-miRNA complexes. Cell Death Differ. 2019;26(7):1346-64.

122. Zheng H, Bi FR, Yang Y, Hong YG, Ni JS, Ma L, et al. Downregulation of miR-196-5p induced by hypoxia drives tumorigenesis and metastasis in hepatocellular carcinoma. Horm Cancer. 2019;10(4-6):177-89.

123. Wu HF, Ren LG, Xiao JQ, Zhang Y, Mao XW, Zhou LF. Long non-coding RNA LINP1 promotes the malignant progression of prostate cancer by regulating p53. Eur Rev Med Pharmacol Sci. 2021;25(5):2158.

124. Mantovani F, Collavin L, Del Sal G. Mutant p53 as a guardian of the cancer cell. Cell Death Differ. 2019;26(2):199-212.

125. Li Y, Cao Y, Xiao J, Shang J, Tan Q, Ping F, et al. Inhibitor of apoptosis-stimulating protein of p53 inhibits ferroptosis and alleviates intestinal ischemia/reperfusion-induced acute lung injury. Cell Death Differ. 2020;27(9):2635-50.

126. Celardo I, Melino G, Amelio I. Commensal microbes and p53 in cancer progression. Biol Direct. 2020;15(1):25. 
127. Soliman L, De Souza A, Srinivasan P, Danish M, Bertone P, El-Deiry WS, et al. The role of BCL-2 proteins in the development of castrationresistant prostate cancer and emerging therapeutic strategies. Am J Clin Oncol. 2021;44(7):374-82.

128. Warren CFA, Wong-Brown MW, Bowden NA. BCL-2 family isoforms in apoptosis and cancer. Cell Death Dis. 2019;10(3):177.

129. Xie W, Guo H, Zhang J, Hu L, Wu Y, Wang X. Comprehensive analysis of the relationship between metabolic reprogramming and immune function in prostate cancer. Onco Targets Ther. 2021;14:3251-66.

130. Rohena-Rivera K, Sanchez-Vazquez MM, Aponte-Colon DA, Forestier-Roman IS, Quintero-Aguilo ME, Martinez-Ferrer M. IL-15 regulates migration, invasion, angiogenesis and genes associated with lipid metabolism and inflammation in prostate cancer. PLoS ONE. 2017;12(4):e0172786.

131. Sumsion GR, Bradshaw MS 3rd, Beales JT, Ford E, Caryotakis GRG, Garrett DJ, et al. Diverse approaches to predicting drug-induced liver injury using gene-expression profiles. Biol Direct. 2020;15(1):1.

132. Han Y, Ye X, Wang C, Liu Y, Zhang S, Feng W, et al. Integration of molecular features with clinical information for predicting outcomes for neuroblastoma patients. Biol Direct. 2019;14(1):16.

133. Han Y, Ye X, Cheng J, Zhang S, Feng W, Han Z, et al. Integrative analysis based on survival associated co-expression gene modules for predicting Neuroblastoma patients' survival time. Biol Direct. 2019;14(1):4.

134. Madera S, Chervo MF, Chiauzzi VA, Pereyra MG, Venturutti L, Izzo F, et al. Nuclear PDCD4 expression defines a subset of luminal B-like breast cancers with good prognosis. Horm Cancer. 2020;11(5-6):218-39.

135. Zaorsky NG, Calais J, Fanti S, Tilki D, DorffT, Spratt DE, et al. Salvage therapy for prostate cancer after radical prostatectomy. Nat Rev Urol. 2021. https://doi.org/10.1038/s41585-021-00497-7.

136. Fernandez O, Afonso J, Vazquez S, Campos B, Lazaro M, Leon L, et al. Metastatic castration-resistant prostate cancer: changing landscape with cabazitaxel. Anticancer Drugs. 2014;25(3):237-43.

137. Zhu S, Wang Q, Jiang J, Luo Y, Sun Z. A conjugate of methotrexate and an analog of luteinizing hormone releasing hormone shows increased efficacy against prostate cancer. Sci Rep. 2016;6:33894.

138. Green T, Chen X, Ryan S, Asch AS, Ruiz-Echevarria MJ. TMEFF2 and SARDH cooperate to modulate one-carbon metabolism and invasion of prostate cancer cells. Prostate. 2013;73(14):1561-75.

139. Joseph R, Bockorny B, Dasanu CA. Methotrexate therapy leading to a rapid progression of a previously indolent prostate cancer: is immunosuppression to blame? J Oncol Pharm Pract. 2014;20(2):149-53.

140. Kim SY, Jeong HH, Kim J, Moon JH, Sohn KA. Robust pathway-based multi-omics data integration using directed random walks for survival prediction in multiple cancer studies. Biol Direct. 2019;14(1):8.

141. Mihaylov I, Kandula M, Krachunov M, Vassilev D. A novel framework for horizontal and vertical data integration in cancer studies with application to survival time prediction models. Biol Direct. 2019;14(1):22.

142. Teh CE, Gong JN, Segal D, Tan T, Vandenberg CJ, Fedele PL, et al. Deep profiling of apoptotic pathways with mass cytometry identifies a synergistic drug combination for killing myeloma cells. Cell Death Differ. 2020;27(7):2217-33.

143. Wang K, Chen X, Cheng TD, Qiu P, Bird VY, Prosperi M. Association of long-term dynamics in circulating testosterone with serum PSA in prostate cancer-free men with initial-PSA < $4 \mathrm{ng} / \mathrm{mL}$. Horm Cancer. 2019;10(4-6):168-76.

144. Liu L, Wang G, Wang L, Yu C, Li M, Song S, et al. Computational identification and characterization of glioma candidate biomarkers through multi-omics integrative profiling. Biol Direct. 2020;15(1):10.

145. Oktay K, Santaliz-Casiano A, Patel M, Marino N, Storniolo AMV, Torun H, et al. A computational statistics approach to evaluate blood biomarkers for breast cancer risk stratification. Horm Cancer. 2020;11(1):17-33.

146. Ozten N, Vega K, Liehr J, Huang X, Horton L, Cavalieri EL, et al. Role of estrogen in androgen-induced prostate carcinogenesis in NBL rats. Horm Cancer. 2019;10(2-3):77-88.

Publisher's Note Springer Nature remains neutral with regard to jurisdictional claims in published maps and institutional affiliations. 